Cross, H. A., D. Cavanaugh, C. C. Buonanno, and A. Hyman, 2021: The Impact of the Storm Prediction Center's Convective Outlooks and Watches on Emergency Management Operational Planning. J. Operational Meteor., 9 (3), 36-46, doi: https://doi.org/10.15191/nwajom.2021.0903.

Journal of Operational Meteorology
Short Contribution

\title{
The Impact of the Storm Prediction Center's Convective Outlooks and Watches on Emergency Management Operational Planning
}

\author{
HEATHER A. CROSS, DENNIS CAVANAUGH, CHRISTOPHER C. BUONANNO \\ NOAA/National Weather Service, Little Rock, AR \\ AMY HYMAN \\ Arkansas State University, Jonesboro, AR
}

(Manuscript received 11 October 2020; review completed 16 March 2021)

\begin{abstract}
For many emergency managers (EMs) and National Weather Service (NWS) forecasters, Convective Outlooks issued by the Storm Prediction Center (SPC) influence the preparation for near-term severe weather events. However, research into how and when EMs utilize that information, and how it influences their emergency operations plan, is limited. Therefore, to better understand how SPC Convective Outlooks are used for severe weather planning, a survey was conducted of NWS core partners in the emergency management sector. The results show EMs prefer to wait until an Enhanced Risk for severe thunderstorms is issued to prepare for severe weather. In addition, the Day 2 Convective Outlook serves as the threshold for higher, value-based decision making. The survey was also used to analyze how the issuance of different risk levels in SPC Convective Outlooks impact emergency management preparedness compared to preparations conducted when a Convective Watch is issued.
\end{abstract}

\section{Introduction}

Convective Outlooks are routinely issued several times a day by the Storm Prediction Center (SPC). These outlooks highlight areas across the country where both severe and non-severe thunderstorms are anticipated. Areas of possible risk from severe thunderstorms are categorized as "marginal risk", "slight risk", "enhanced risk", "moderate risk", or "high risk", depending on the coverage and strength of the expected severe storms. "High risk" days, while rarely used, tend to verify well. A study of "high risk" forecasts from 2003 to 2009 showed around $64 \%$ of those forecasts verified on tornado warnings alone (Davis et al. 2010). Before the outlooks are published, forecasters at the SPC perform a detailed analysis of recent and current weather data and forecast model output to produce an outlook representative of the current and unfolding atmosphere (Storm Prediction Center 2020).
The Convective Outlooks have continued to change and evolve through the years. For example, in 2012, an increase to the temporal resolution of the Convective Outlooks was researched and implemented experimentally without adding a larger workload for forecasters (Jirak et al. 2012). Regardless of changes to the product, SPC Convective Outlooks have grown in popularity since their origins in the early 1950s (Corfidi 1999). With a growing interest in the SPC Convective Outlooks, emergency managers (EMs) have started to reference the information as it pertains to their jurisdiction in the days and hours leading up to severe weather (Ernst et al. 2018). Additionally, it has been shown that EMs consult the Convective Outlooks early in the planning phase before severe weather occurs (Baumgart et al. 2008). While the National Weather Service (NWS) has the task of sending hazardous weather information out to the public, it is the role of EMs to take the necessary precautions to keep those in

Corresponding author address: Dennis Cavanaugh, 8400 Remount Rd, North Little Rock, AR 72118.

E-mail: dennis.cavanaugh@noaa.gov 
their jurisdiction safe. The EMs take the necessary steps to do this by planning, preparing, and practicing when the weather is quiet. This allows them to implement mitigation techniques when hazardous weather is likely, or imminent, and to build community resilience to the impacts of hazardous weather (Morss and Ralph 2007). When severe weather approaches, EMs respond in a variety of ways from activating notification systems and Emergency Operation Centers (EOCs), to forwarding critical weather warning and additional key information to the public (League et al. 2010).

Convective Watches, classified as either a Severe Thunderstorm Watch (SVA) or a Tornado Watch (TOA), are issued by the SPC when organized severe weather is expected within a two to eight hour period. Convective Watches were first issued in 1952 when the Weather Bureau Army Navy (WBAN) Analysis Center was established. The WBAN Severe Weather Unit, that through the years would eventually evolve into the current day SPC, was responsible for the issuance of weather bulletins, which are essentially what we know today as Convective Watches (Corfidi 1999). An SVA is issued when thunderstorms capable of producing hail of 1-in diameter or larger and/or damaging thunderstorm winds are expected, and a TOA is issued when large hail and damaging winds are possible, as well as tornadoes (Storm Prediction Center 2021). Once in a while, the SPC will include the "Particularly Dangerous Situation (PDS)" statement in TOAs when long-lived and intense tornadoes are likely. Additionally, the PDS Watches are typically issued when there is a "high risk" included in the Day 1 Convective Outlook (Storm Prediction Center 2021).

In addition to the protection of life, the NWS and agency core partners have the mission of mitigating the loss of property attributable to hazardous weather events. Historic events show that the dissemination of critical weather information leading up to severe weather can save millions of dollars (Grice et al. 1999). Previous research by League et al. in 2010 shows that the majority of EMs use NWS products, especially watches and warnings. However, research into how EMs prepare in the Day 1 to 8 period leading up to a severe weather event, and how products issued by the SPC impact that, is lacking. Through the years, SPC's Convective Outlooks have transitioned from a generic tornado forecast into the risk categories ranging from "general thunder" to "high" that we know today (Corfidi 1999). Past studies show that the best method for managing weather information is through direct contact with the NWS and EMs (Hoss and Fischbeck 2018). This suggests that, while it is very easy to find and view the SPC Convective Outlook with today's technology, understanding outlooks might not be as simple, especially for those EMs unfamiliar with - or without an educational background in - meteorology (Weaver et al. 2014). Furthermore, even with a firm understanding of the Convective Outlooks, how an EM uses those in the planning and preparation phase leading up to a severe weather event is unknown.

This research aims to determine when in Days 1 to 8 leading up to a severe weather event, and at what Convective Outlook level, EMs begin altering their normal routine to prepare for hazardous weather. This study also explores how EMs alter their operations when a Convective Watch is issued, and whether or not the type of watch impacts those changes.

\section{Data and methods}

A survey was developed to better understand when, and at what Convective Outlook level, EMs enact their severe weather operations plan to change their routine and prepare for hazardous weather based on information from the SPC. The SPC is also responsible for issuing Convective Watches to alert the public and EMs when conditions are favorable for the development of severe thunderstorms and/or tornadoes within the proceeding hours (Storm Prediction Center 2020), so pertinent questions were included in the survey. This grouping also included PDS Watches to determine what difference in planning, if any, this would cause when issued compared to a typical Convective Watch.

The survey was created and disseminated online in the spring of 2018 using Google Forms, and can be viewed in Appendix A. The survey link was sent via email to EMs and four other NWS Warning Coordination Meteorologists, who forwarded the survey link to EMs in their forecast area. In all, the survey was disseminated to approximately 160 state, county, city, and private sector EMs throughout Arkansas, Oklahoma, and portions of Texas and Tennessee. Eighty-four EMs completed and returned the survey, resulting in a response rate just $\geq 50 \%$. While the survey was primarily distributed online, it was also handed out at an Integrated Warning Team meeting to Arkansas EMs. Around 10 surveys were completed on paper, and then entered into the Google Form manually by the authors in order to compile all responses. Google Forms allows users to adjust settings within the survey before sending it out. 
For this research, email addresses were not collected, users were not required to sign in, and there was no limit on responses. Additionally, respondents could not edit their answers after submission, nor could they view summary charts and text responses.

To simplify the process of data acquisition and analysis, the team decided to use multiple-choice questions rather than ones that would lead to openended responses. Although allowing EMs to answer with an open-ended response would provide more information overall, it was decided that closed-ended survey questions would meet the researchers' goal of identifying thresholds and significant differences in the decisions EMs make using the SPC's products, and thus were ultimately used instead of open-ended questions. In proceeding with the multiple-choice questions, authors included ways for EMs to opt out of answering questions. While "other" was not an answer choice for any survey questions, respondents could choose not to answer questions that were not required, and for those that were required, a final option of "I don't use SPC Convective Outlooks" or "No impact" were included. Moreover, survey respondents were anonymous, so they had nothing to lose or gain by selecting an option that did not correctly reflect their operations in the given scenarios. Finally, in an attempt to limit potential NWS perception and bias in the survey that could influence the results, a professor of emergency management from Arkansas State University was consulted to create and finalize the survey.

The survey included questions such as state residency, emergency management jurisdiction/size, and primary sources for weather information. However, the bulk of the survey consisted of specific questions pertaining to emergency operations plans for severe weather based on the SPC Convective Outlooks and Watches. These questions were intended to discover if and how each SPC product affects operations (e.g., differences in planning, if any, caused by an "enhanced risk" as opposed to a "moderate risk" on Day 1; differences in resource allocation caused by a SVA compared to a TOA, etc.). When asked how their operations would be impacted by Convective Outlooks, EMs could choose watching the weather more closely, sending out additional information, beginning daily briefings, cancelling events, and changing staffing levels. However, these questions were not required and EMs were only asked to answer these particular questions if they used SPC Convective Outlooks. Additionally, response choices regarding Convective
Watches included watching the weather more closely/ monitoring radar, sending out information, beginning briefings, cancelling events, watching local news for weather information, calling the local NWS/monitoring NWSChat, deploying trained weather spotters, and no impact.

As mentioned above, one of the goals of the survey was to determine what risk level on Days 1 to 8 prompts EMs to take action. However, the team also wanted to analyze the value of the decisions made by the EM, because in most cases this plays a critical role in determining what action is taken. In particular, when financial implications are in play it can be especially stressful for decision makers because they could be open to steeper criticism depending on how the event plays out (Ernst et al. 2018). To assess how much attention an EM gives to a weather event, (1s) and (2s) were assigned to the answer choices for each question. A (1) indicated that the decisions made required no additional financing or resources, whereas a (2) indicated that decisions made required additional money and resources. A zero was assigned to those responses that indicated "no impact". Because more than one decision could be made because of the "check all that apply" format, the sum of each value-weighted decision chosen was taken and used for statistical analysis for each applicable question.

Although the method above allowed researchers to gauge how each outlook impacted the EM's focus on a weather event, it didn't necessarily accurately reflect the financial weighted decisions. This is because multiple answers could be chosen. Therefore, it was possible for an EM to choose three answers rated a (1) with a sum of 3 , while another EM could have chosen only one option rated a (2), making it seem that more resources were spent with the sum of 3 rather than the sum of 2 . To resolve this problem, researchers re-ran statistical tests and changed the (1s) to $(0 s)$ and $(2 s)$ to $(1 s)$. This would result in a sum of (0) unless the choices that required additional money and resources were chosen (1s).

\section{Discussion and analysis}

In all, there were 84 responses to the survey, 29 from Arkansas, 18 from Tennessee, three from Texas, and 34 from Oklahoma. The majority of the responses were from county EMs, however there were several state and city EMs represented, and two private enterprise EMs represented as well. Jurisdiction population sizes ranged from $\leq 2500$ to $\geq 3000000$. Although most EMs who took the survey indicated a jurisdiction size $\leq 2500$, 
almost a quarter reported a population size between 300000 and 999 999. In addition to other generalized questions, it was of interest to determine how many EMs are even aware of the SPC's Convective Outlooks. As seen in Fig. 1, of those surveyed, 81\% answered "Yes" to this question, leaving $19 \%$ who answered "No". EMs were also asked if they had an emergency operation plan for severe weather, which $98 \%$ of those surveyed did. Survey results, seen in Fig. 2, show that for $66 \%$ of EMs, their main source of weather information comes from the local NWS Weather Forecast Office, with weather apps on a smartphone the second most common source of weather information. The SPC, was well represented, but only the main source of weather information for roughly $12 \%$ of EMs, meaning that although they view SPC's products, it isn't necessarily where they go first or most frequently for weather information. It is important to mention, however, that many NWS offices utilize, agree with, and message the SPC Convective Outlooks in their products. Therefore, even if EMs do not go to SPC directly as a primary source, they are still using the SPC information via their local forecast office.

To analyze the survey results with respect to those EMs that use SPC Outlooks, a Kruskal-Wallis test [Weiss (2008); Albright and Winston (2015); Stat Tools (2020)] was performed to determine what level of SPC Outlook prompted/impacted decision making. A Kruskal-Wallis test is a non-parametric method used for comparing two or more independent samples of equal or different sample sizes. We wanted to test three independent samples of SPC Outlooks (e.g., Days 1 to 3) based on EM responses, therefore, the Kruskal-Wallis test was chosen because the distribution of results was not likely to fall into a normal (Gaussian) distribution. This non-parametric test is a variation of a one-way analysis of variance (ANOVA), but is not based on the assumption that the sample size must be normally distributed to derive statistically significant results. Of the 84 EMs surveyed, 16 indicated that they were not aware of SPC Outlooks, and thus did not use them to make any planning decisions. This left 68 respondents to use for the Kruskal-Wallis test to analyze at what categorical risk level EMs started making some valuebased decisions (Fig. 3). This test showed that EMs who use SPC Outlooks to make value-based decisions on average made those decisions when their jurisdiction was in an "enhanced risk" area (4 out of 6) based on SPC's threat categories. Furthermore, results from the survey in Fig. 4 show that roughly $90 \%$ of the EMs who use SPC Outlooks wait to make high value decisions until their area is at least under a "slight risk" in the Days 1 to 3 period, but that approximately half prefer to wait until their area is under an "enhanced risk" or greater.

As discussed above, the authors assigned (2s) to any decisions EMs made in Days 1 to 8 leading up to a severe weather event that required additional money or resources. The sum of these were then incorporated into a Kruskal-Wallis test to analyze which day had the greatest impact on EM decision making (Table 1). The results support the finding that EMs start making most of their higher value-based decisions on Day 2 . Therefore, the Convective Outlook issued by the SPC on Day 2 plays a critical role in how EMs prepare for a severe weather event.

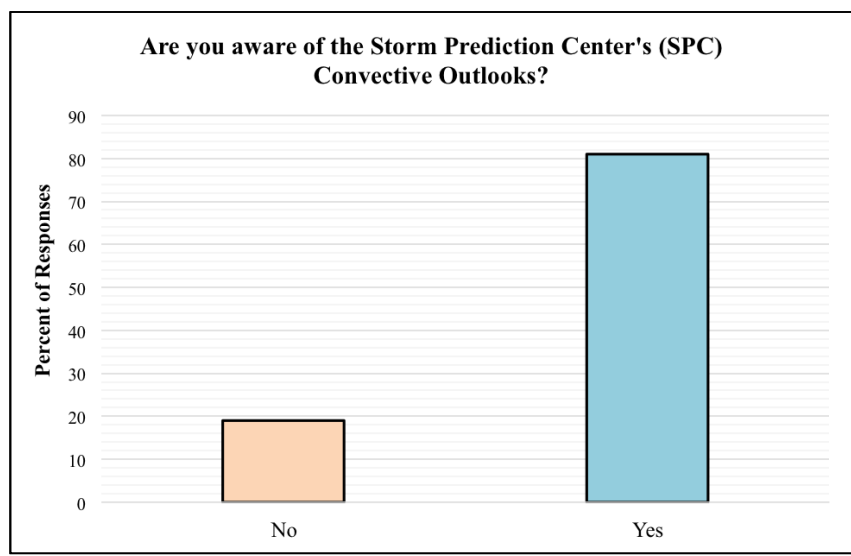

Figure 1. Bar graph showing the spread of how many EMs are aware of Storm Prediction Center Convective Outlooks. Click image for an external version; this applies to all figures hereafter.

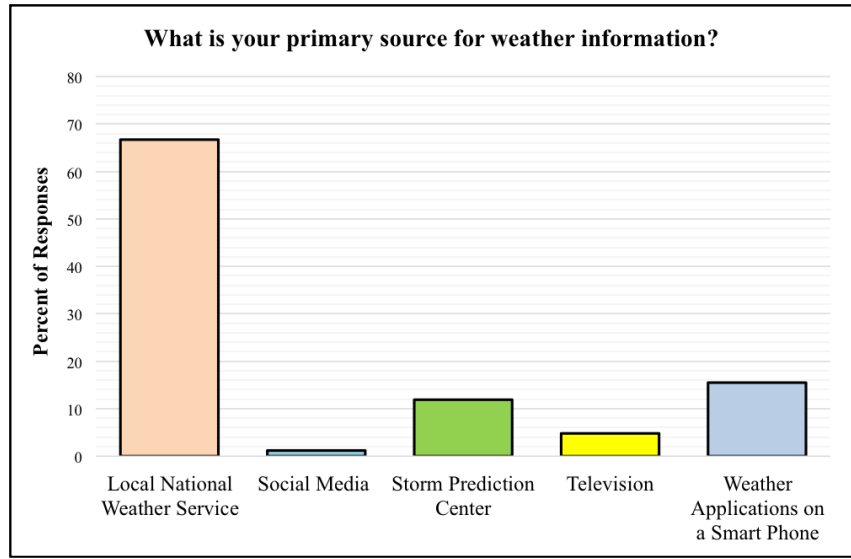

Figure 2. Bar graph showing the main source of weather information used by EMs. 
Table 1. Kruskal-Wallis Test analyzing the threshold at which EMs stated in the survey they started making decisions on Days 1 to 8. The results show that EMs begin to make value-based decisions on Day 2, which places high importance on that convective outlook.

\begin{tabular}{|l|c|c|c|c|}
\hline & $\begin{array}{c}\text { Day 1 } \\
\text { Decision } \\
\text { Threshold }\end{array}$ & $\begin{array}{c}\text { Day 2 } \\
\text { Decision } \\
\text { Threshold }\end{array}$ & $\begin{array}{c}\text { Day 3 } \\
\text { Decision } \\
\text { Threshold }\end{array}$ & $\begin{array}{c}\text { Days 4 to 8 } \\
\text { Decision } \\
\text { Threshold }\end{array}$ \\
\hline Sample Size & 68 & 68 & 68 & 68 \\
\hline Sample Mean & 0.44 & 0.38 & 0.00 & 0.00 \\
\hline Sample Standard Deviation & 0.90 & 0.86 & 0.00 & 0.00 \\
\hline Sample Median & 0 & 0 & 0 & 0 \\
\hline
\end{tabular}

In addition to the Convective Outlook period, EMs were also asked about decisions they make during the Convective Watch phase of an anticipated thunderstorm event. EMs were asked to list their decisions made for the following types of Convective Watches; a SVA, a TOA, and a TOA with a PDS designation. Because watches are not ranked by severity (e.g., the probability metadata included within the watch issuance on the SPC watch page), a non-parametric hypothesis test was performed for the pairs of watch types to determine if there was a statistically significant difference in decision making by the EM community based on the type of watch issued. Mann-Whitney tests [Mann and Whitney, 1947, Weiss, 2008, and Stat Tools, 2020] were performed for each pairing of watch type, and for each pair, these tests indicated that there was a statistically significant difference in the amount of decisions made based on the type of watch that is issued preceding a high-impact thunderstorm event (Tables 2-4). A Kruskal-Wallis test was also conducted using the method with $(0 \mathrm{~s})$ and $(1 \mathrm{~s})$ to take the findings further and determine if EMs are also spending more resources for a TOA and PDS Watch than an SVA. The KruskalWallis test showed that, in fact, this was true (Table 5). These results indicate that EMs change their operations more and make higher value-based decisions based on the type of Convective Watch issued. Moreover, the Mann-Whitney test results provide strong evidence that EMs pay more attention and spend more resources when a TOA is issued compared to an SVA. Finally, results show that EMs are more focused on PDS Watches when compared to TOAs or SVAs. This suggests the importance of forecasting and communicating the convective threat severity in the hours leading up to a hazardous weather event.

Last, EMs responded to the survey from a large disparity of populations served. In general, EMs responsible for a larger population area tend to have

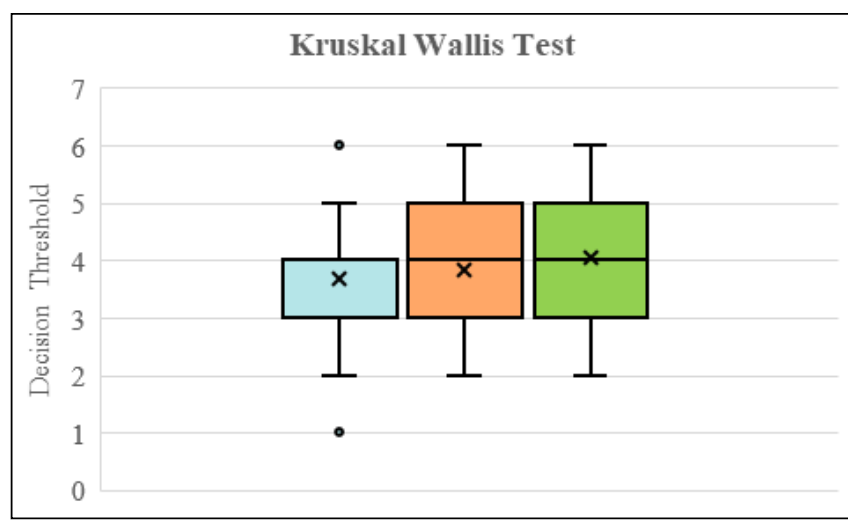

Figure 3. Box and whisker plot representing the results of a Kruskal-Wallis test with Day 1 depicted in orange, Day 2 in blue, and Day 3 in green. The test shows that Day 1 compared to Day 3 reflects the largest difference between high value decision-making thresholds. However, it also shows that most EMs start making decisions to change their operations or start monitoring the weather more closely when the SPC outlook reaches a level 4 out of 6 (i.e., an "enhanced risk").

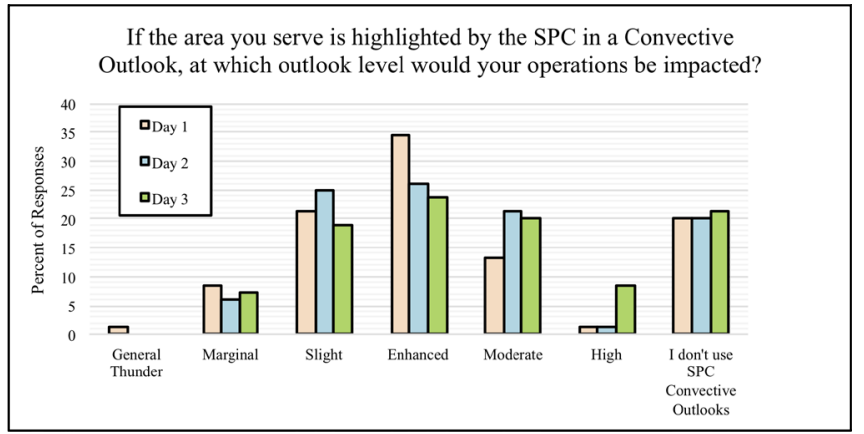

Figure 4. Clustered column chart showing at which outlook level on Days 1 to 3 emergency operations are impacted. 
Table 2. Mann-Whitney test results using the (1) and (2) method comparing the decision-making for SVAs compared to TOAs.

\begin{tabular}{|l|l|c|}
\hline & \multicolumn{1}{|c|}{ SVA Decision Value } & TOA Decision Value \\
\hline Sample Size & \multicolumn{1}{|c|}{84} & \multicolumn{1}{|c|}{2.93} \\
\hline Sample Mean & \multicolumn{1}{|c|}{2.2} & 4.91 \\
\hline Sample Standard Deviation & \multicolumn{1}{|c|}{ Mann-Whitney Test } \\
\hline Sample Median & Neither Dist. Smaller \\
\hline \multicolumn{1}{|c|}{ SVA Decision Value Smaller } \\
\hline Null Hypothesis & 168 \\
\hline Alternative Hypothesis & 168 \\
\hline Number of Values in Ranking & 5588.5 \\
\hline Number of Tied Values & 8607.5 \\
\hline Rank Sum for Variable 1 & Yes \\
\hline Rank Sum for Variable 2 & No \\
\hline Normal Approximation (NA) Used & 7098 \\
\hline Ties Present, but Not Corrected For & 312.74 \\
\hline Mean for NA & -4.83 \\
\hline Standard Deviation for NA with Tie Correction & $<0.0001$ \\
\hline z-Statistic for NA with Tie Correction & Reject \\
\hline p-Value & Reject \\
\hline Null Hypothesis at 10\% Significance & Reject \\
\hline Null Hypothesis at 5\% Significance & \\
\hline Null Hypothesis at 1\% Significance & \multicolumn{1}{|c|}{} \\
\hline
\end{tabular}

more resources available to deploy if a high-impact weather event affects the community they serve. In lieu of asking EMs how much money they spent in terms of time, personnel, and resources, the survey asked for relative decisions being made that may result in a response to an impactful weather event. This method was used to avoid quantifying a large financial disparity from EMs representing smaller communities compared to larger communities. The relative cost of dedicating resources is assumed to be proportional to community size, resources, and money available. To test this hypothesis, the relative value-based decisionmaking tabulated from the survey was compared to EMs representing a multitude of population categories using a linear regression. With this technique, the sum of each value-based decision for a PDS Convective Watch was represented as the dependent variable leaving population size served as the independent variable (Table 6). The PDS was the best option for the regression test (compared to Outlook Day 1, TOA, SVA, etc.) because it resulted in the highest amount of valuebased decisions. The resultant regression coefficient and associated $p$-value indicate that population size is not a good indicator of value-based decision-making by EMs. This regression provides strong support that population size and resource availability did not skew the results of the relative value of decision making by EMs that responded to this survey.

\section{Summary and conclusion}

The EMs that responded to this survey are using the SPC Convective Outlook and Convective Watch products to help prepare for hazardous weather, and this research provides novel insight into how the EM community uses those products to prepare communities before and during severe weather events. One limitation of this research included a smaller sample size than originally desired, with only 84 respondents. However, completed surveys still provided an adequate amount of data for analysis and thus resulted in worthwhile and meaningful statistical results. Although EMs from several different states were included in the survey dissemination, a larger sample size from Texas, 
Table 3. Mann-Whitney test results using the (1) and (2) method comparing the decision-making for TOAs compared to PDS TOAs.

\begin{tabular}{|c|c|c|}
\hline & SVA Decision Value & TOA Decision Value \\
\hline Sample Size & 84 & 84 \\
\hline Sample Mean & 4.91 & 6.18 \\
\hline Sample Standard Deviation & 2.72 & 3.11 \\
\hline Sample Median & 5 & 6 \\
\hline \multicolumn{3}{|c|}{ Mann-Whitney Test } \\
\hline Null Hypothesis & \multicolumn{2}{|l|}{ Neither Dist. Smaller } \\
\hline Alternative Hypothesis & \multicolumn{2}{|c|}{ TOA Decision Value Smaller } \\
\hline Number of Values in Ranking & \multicolumn{2}{|l|}{168} \\
\hline Number of Tied Values & \multicolumn{2}{|l|}{167} \\
\hline Rank Sum for Variable 1 & \multicolumn{2}{|l|}{6261} \\
\hline Rank Sum for Variable 2 & \multicolumn{2}{|l|}{7935} \\
\hline Normal Approximation (NA) Used & \multicolumn{2}{|l|}{ Yes } \\
\hline Ties Present, but Not Corrected For & \multicolumn{2}{|l|}{ No } \\
\hline Mean for NA & \multicolumn{2}{|l|}{7098} \\
\hline Standard Deviation for NA with Tie Correction & \multicolumn{2}{|l|}{313.54} \\
\hline z-Statistic for NA with Tie Correction & \multicolumn{2}{|l|}{-2.6679} \\
\hline p-Value & \multicolumn{2}{|l|}{0.0038} \\
\hline Null Hypothesis at $10 \%$ Significance & \multicolumn{2}{|l|}{ Reject } \\
\hline Null Hypothesis at 5\% Significance & \multicolumn{2}{|l|}{ Reject } \\
\hline Null Hypothesis at $1 \%$ Significance & \multicolumn{2}{|l|}{ Reject } \\
\hline
\end{tabular}

Oklahoma, and Tennessee could have allowed the data to be broken down even further. If this is attained in future research, the authors would aim to determine what impact, if any, location plays on EM operational planning in response to the SPC products.

When the NWS better understands the decision thresholds of their core partners, they can provide forecasts and briefings that target important emergency operations plans and this would help all partners to collaborate on improving community resilience. This is especially helpful for EMs and the NWS regarding threats in the Convective Outlooks. For example, when local NWS offices know EMs prefer to wait until an Enhanced Risk is issued in the Convective Outlook to prepare for severe weather, it can directly impact when key information is relayed or presented during briefings. This research also helps the NWS and EM communities identify thresholds in which finite resources are being used. This is primarily shown by the importance of the Day 2 Convective Outlook as a common threshold for higher value-based decision-making by EMs. It is also reflected in the SVA impact on operational planning versus a TOA, as well as the added significance of the PDS designation on EM preparedness. If the NWS and EM communities are aware of these thresholds in valuebased decision-making, they may be able to optimize resources while maintaining a high level of community resilience to hazardous weather events.

Acknowledgments. Thank you to NWS Norman, NWS Fort Worth/Dallas, NWS Memphis, and NWS Nashville for disseminating the survey to EMs in their forecast areas, which helped widen the sample size and improve research analysis. The authors also thank all the EMs who took the time to take the survey, and the reviewers who helped improve the manuscript through thoughtful comments and suggestions. 
Table 4. Mann-Whitney test results using the (1) and (2) method comparing the decision-making between SVAs and PDS TOAs.

\begin{tabular}{|c|c|c|}
\hline & SVA Decision Value & TOA Decision Value \\
\hline Sample Size & 84 & 84 \\
\hline Sample Mean & 2.93 & 6.18 \\
\hline Sample Standard Deviation & 2.24 & 3.11 \\
\hline Sample Median & 3 & 6 \\
\hline \multicolumn{3}{|c|}{ Mann-Whitney Test } \\
\hline Null Hypothesis & \multicolumn{2}{|l|}{ Neither Dist. Smaller } \\
\hline Alternative Hypothesis & \multicolumn{2}{|c|}{ SVA Decision Value Smaller } \\
\hline Number of Values in Ranking & \multicolumn{2}{|l|}{168} \\
\hline Number of Tied Values & \multicolumn{2}{|l|}{168} \\
\hline Rank Sum for Variable 1 & \multicolumn{2}{|l|}{5006} \\
\hline Rank Sum for Variable 2 & \multicolumn{2}{|l|}{9190} \\
\hline Normal Approximation (NA) Used & \multicolumn{2}{|l|}{ Yes } \\
\hline Ties Present, but Not Corrected For & \multicolumn{2}{|l|}{ No } \\
\hline Mean for NA & \multicolumn{2}{|l|}{7098} \\
\hline Standard Deviation for NA with Tie Correction & \multicolumn{2}{|l|}{313.41} \\
\hline z-Statistic for NA with Tie Correction & \multicolumn{2}{|l|}{-6.67} \\
\hline p-Value & \multicolumn{2}{|l|}{$<0.0001$} \\
\hline Null Hypothesis at $10 \%$ Significance & \multicolumn{2}{|l|}{ Reject } \\
\hline Null Hypothesis at 5\% Significance & \multicolumn{2}{|l|}{ Reject } \\
\hline Null Hypothesis at $1 \%$ Significance & \multicolumn{2}{|l|}{ Reject } \\
\hline
\end{tabular}

Table 5. Kruskal-Wallis Test using the (0) and (1) method showing that EMs make higher value-based decisions when a TOA or PDS Watch is than they do when an SVA is issued.

\begin{tabular}{|l|c|c|c|}
\hline & $\begin{array}{c}\text { SVA Decision } \\
\text { Threshold }\end{array}$ & $\begin{array}{c}\text { TOA Decision } \\
\text { Threshold }\end{array}$ & $\begin{array}{c}\text { PDS Decision } \\
\text { Threshold }\end{array}$ \\
\hline Sample Size & 84 & 84 & 84 \\
\hline Sample Mean & 0.19 & 0.80 & 1.30 \\
\hline Sample Standard Deviation & 0.40 & 0.88 & 1.06 \\
\hline Sample Median & 0 & 1 & 1 \\
\hline
\end{tabular}


Table 6. Regression analysis with all emergency management value-based decisions set as dependent variables for PDS SPC Watches. The independent variable is population size represented by the EMs. The p-Value associated with each independent variable suggests that population size represented was not a good discriminator of relative value-based decisions. These results suggest that relative value-based decisions were not dependent upon population size represented.

\begin{tabular}{|c|c|c|c|c|c|c|}
\hline \multicolumn{7}{|c|}{ Regression for PDS Watch } \\
\hline & Multiple R & R-Square & $\begin{array}{l}\text { Adjusted } \\
\text { R-Square }\end{array}$ & $\begin{array}{c}\text { Standard } \\
\text { Error of } \\
\text { Estimate }\end{array}$ & $\begin{array}{c}\text { Rows Ig- } \\
\text { nored }\end{array}$ & $\begin{array}{l}\text { Rows Ig- } \\
\text { nored }\end{array}$ \\
\hline Summary & 0.07 & 0.01 & 0.00 & 2.13 & 0 & 0 \\
\hline \multicolumn{7}{|c|}{ ANOVA Table } \\
\hline & $\begin{array}{c}\text { Degrees of } \\
\text { Freedom }\end{array}$ & $\begin{array}{l}\text { Sum of } \\
\text { Squares }\end{array}$ & $\begin{array}{l}\text { Mean of } \\
\text { Squares }\end{array}$ & $\mathbf{F}$ & \multicolumn{2}{|c|}{ p-Value } \\
\hline Explained & 1 & 1.77 & 1.77 & 0.39 & \multicolumn{2}{|c|}{0.53} \\
\hline Unexplained & 82 & 372.47 & 4.54 & & & \\
\hline \multicolumn{7}{|c|}{ Regression Table } \\
\hline $\begin{array}{l}\text { Decision } \\
\text { Value }\end{array}$ & Coefficient & $\begin{array}{c}\text { Standard } \\
\text { Error }\end{array}$ & t-Value & p-Value & \multicolumn{2}{|c|}{$\begin{array}{cc}\text { Confidence } & \text { Interval 95\% } \\
\text { Lower } & \text { Upper } \\
\end{array}$} \\
\hline Constant & 2.91 & 0.56 & 5.19 & $<0.0001$ & 1.80 & 4.03 \\
\hline Population & -0.12 & 0.19 & -0.62 & 0.53 & -0.50 & 0.26 \\
\hline
\end{tabular}

\title{
APPENDIX A
}

\section{Survey Questions}

Impacts of the Storm Prediction Center's Convective Outlooks on Emergency Management (* Required)

1. What state are you in? *

2. What are you an Emergency Manager of? *
$\square$ Medical Facility
$\square$ State
$\square$ County
$\square$ Educational Facility
$\square$ Event Center
$\square$ City
$\square$ Shopping Center

3. On any given day, what population size do you serve? *
$\square<2500$
$\square 2,500-49,999$
$\square 50,000-99,999$
$\square 100,000-999,999$
$\square 1,000,000-3,000,000$
$\square>3$ Million

4. What is your primary source for weather information? $*$
$\square$ Weather apps on a smart phone
$\square$ Storm Prediction Center
$\square$ Radio

\author{
$\square$ Television \\ $\square$ Social Media \\ $\square$ Local National Weather Service
}

5. Do you have an Emergency Operations Plan for severe weather? *
$\square$ Yes
$\square$ No 
6. Are you aware of the Storm Prediction Center's (SPC) Convective Outlooks? *

$\square$ Yes $\square$ No

7. If on Day 1, the area that you serve is highlighted by SPC in a Convective Outlook, at which outlook level would your operations procedure be impacted? *
$\square$ General Thunder
$\square$ Marginal
$\square$ Slight
$\square$ Enhanced
$\square$ Moderate
$\square$ High
$\square$ I don’t use SPC Convective Outlooks

7a. How? (Please answer if you use SPC Convective Outlooks)

$\square$ Watch the weather forecast more closely

$\square$ Send out information

$\square$ Begin daily briefings

$\square$ Cancel events

$\square$ Change staffing levels

8. If on Day 2, the area that you serve is highlighted by SPC in a Convective Outlook, at which outlook level would your operations procedure be impacted? *
$\square$ General Thunder
$\square$ Marginal
$\square$ Moderate
$\square$ High
$\square$ Slight
$\square$ Enhanced
$\square$ I don't use SPC Convective Outlooks

8a. How? (Please answer if you use SPC Convective Outlooks)

$\square$ Watch the weather forecast more closely

$\square$ Send out information

$\square$ Begin daily briefings

$\square$ Cancel events

$\square$ Change staffing levels

9. If on Day 3, the area that you serve is highlighted by SPC in a Convective Outlook, at which outlook level would your operations procedure be impacted? *
$\square$ General Thunder
$\square$ Marginal
$\square$ Slight
$\square$ Enhanced
$\square$ Moderate
$\square$ High
$\square$ I don’t use SPC Convective Outlooks

9a. How? (Please answer if you use SPC Convective Outlooks)

$\square$ Watch the weather forecast more closely

$\square$ Begin daily briefings

$\square$ Send out information

$\square$ Change staffing levels

$\square$ Cancel events

10. If on Days 4-8, the area you serve is highlighted by SPC in a Convective Outlook, at which outlook level would your operations procedure be impacted? *
$\square 15 \%$
$\square 30 \%$
$\square$ I don’t use SPC Convective Outlooks

10a. How? (Please answer if you use SPC Convective Outlooks)

$\square$ Watch the weather forecast more closely

$\square$ Begin daily briefings

$\square$ Send out information

$\square$ Change staffing levels

$\square$ Cancel events

11. How are your operations impacted when the area you serve is placed under a Severe Thunderstorm Watch? *

$\square$ Watch the weather forecast more closely/Monitor Radar

$\square$ Send information out

$\square$ Begin briefings

$\square$ Cancel events

$\square$ Change staffing levels

$\square$ Watch local news for weather information

$\square$ Call your local National Weather Service/Monitor NWSChat

$\square$ Deploy trained weather spotters $\square$ No impact 
12. How are your operations impacted when the area you serve is placed under a Tornado Watch? *

$\square$ Watch the weather forecast more closely/Monitor Radar

$\square$ Send information out

$\square$ Begin briefings

$\square$ Cancel events

$\square$ Change staffing levels

$\square$ Watch local news for weather information

$\square$ Call your local National Weather Service/Monitor NWSChat

$\square$ Deploy trained weather spotters $\quad \square$ No impact

13. How are your operations impacted when the area you serve is placed under a Particularly Dangerous Situation (PDS) Watch?*

$\square$ Watch the weather forecast more closely/Monitor Radar

$\square$ Send information out $\quad \square$

$\square$ Cancel events

$\square$ Begin briefings

$\square$ Watch local news for weather information

$\square$ Change staffing levels

$\square$ Call your local National Weather Service/Monitor NWSChat

$\square$ Deploy trained weather spotters $\quad \square$ No impact

\section{REFERENCES}

Albright, C. S., and W. Winston, 2015: Business Analytics, Data Analysis and Decision Making, 5th Edition. Cengage Learning. 990 pp.

Baumgart, L. A., E. J. Bass, B. Phillips, and K. Kloesel, 2008: Emergency management decision making during severe weather. Wea. Forecasting, 23, 1268-1279. CrossRef.

Corfidi, S. F., 1999: The birth and early years of the Storm Prediction Center. Wea. Forecasting, 14, 507-525 CrossRef.

Davis, J. M., A. R. Dean, and J. L. Guyer, 2010: A detailed analysis of SPC "high risk" outlooks, 2003-2009. Preprints, 25th Conf. Severe Local Storms, Denver, CO, Amer. Meteor. Soc. 8B.6. [Available online at: ams.confex.com/ams/pdfpapers/176214.pdf].

Ernst, S., D. LaDue, and A. Gerard, 2018: Understanding emergency manager forecast use in severe weather events. J. Operational Meteor., 6 (9), 95-105. CrossRef.

Grice, G. K., and Coauthors, 1999: The golden anniversary of the first tornado forecasts. Bull. Amer. Meteor. Soc., 80, 1341-1348. CrossRef.

Hoss, F., and P. Fischbeck, 2018: Use of observational weather data and forecasts in emergency management: an application of the theory of planned behavior. Wea. Climate Soc., 10, 275-290. CrossRef.

Jirak, I. L., C. J. Melick, A. R. Dean, S. J. Weiss, and J. Correia Jr., 2012: Investigation of an Automated Temporal Disaggregation Technique for Convective Outlooks during the 2012 Hazardous Weather Testbed Spring Forecasting Experiment. Preprints 26th Conf. Severe Local Storms, Nashville, TN, 10.2. [Available online at: ams.confex.com/ams/26SLS/webprogram/ Paper211733.html].
League, C. E., W. Diaz, B. Philips, E. J. Bass, K. Kloesel, E. Gruntfest, and A. Gessner, 2010: Emergency manager decision-making and tornado warning communication, Meteorol. Appl., 17 (2), 163-172. CrossRef.

Mann, H. B., and D. R. Whitney, 1947: On a test of whether one of two random variables is stochastically larger than the other. Ann. Math. Statist., 18 (1): 50-60. CrossRef.

Morss, R. E., and F. M. Ralph, 2007: Use of information by National Weather Service forecasters and emergency managers during CALJET and PACJET-2001. Wea. Forecasting, 22, 539-555. CrossRef.

Palisade Inc., 2020: Stat Tools. [Available online at www.palisade.com/stattools/default.asp].

Storm Prediction Center, cited 2020: About the SPC. [Available online at www.spc.noaa.gov/misc/aboutus. html].

, 2021: Frequently Asked Questions. [Available online at: www.spc.noaa.gov/faq].

Weaver, J., L. C. Harkabus, J. Braun, S. Miller, R. Cox, J. Griffith, and R. J. Mazur, 2014: An overview of a demographic study of United States emergency managers. Bull. Amer. Meteor. Soc., 95, 199-203. CrossRef.

Weiss, N., 2008: Introductory Statistics, 8th Edition. Pearson. $881 \mathrm{pp}$. 